Laser Chem., 1999, Vol. 19, pp. 317-320

Reprints available directly from the publisher Photocopying permitted by license only
(C) 1999 OPA (Overseas Publishers Association) N.V. Published by license under the Harwood Academic Publishers imprint, part of The Gordon and Breach Publishing Group.

\title{
TRANSIENT ABSORPTION SPECTRA OF VIBRATIONALLY EXCITED WATER MOLECULE ON ZEOLITE SURFACE
}

\author{
TATSUYA FUJINO $^{\text {a }}$, AKIHIDE WADA $^{\mathrm{a}}$, SATORU S. KANO $^{\mathrm{b}}$, \\ KAZUNARI DOMEN ${ }^{\mathrm{a}}$ and CHIAKI HIROSE ${ }^{\mathrm{a}, *}$ \\ ${ }^{a}$ Research Laboratory of Resources Utilization, Tokyo Institute of Technology, \\ 4259 Nagatsuta, Midori-ku, Yokohama 226, Japan; \\ ${ }^{\mathrm{b}}$ College of Engineering, Hosei University, Koganei, Tokyo 184, Japan
}

(Received 7 April 1997)

By means of infrared pump-probe technique, spectroscopic feature of vibrationally excited water molecule $\left(\mathrm{D}_{2} \mathrm{O}\right)$ on mordenite zeolite $(\mathrm{OD})$ has been investigated. Populational lifetime of the OD stretching band $\left(v_{3}: 2730 \mathrm{~cm}^{-1}\right)$ was determined to be $43 \pm 5 \mathrm{ps}$ at $123 \mathrm{~K}$ by the time evolution of hot band. The transient bleachings and absorptions appeared when the $\mathrm{D}_{2} \mathrm{O}$ molecule was promoted to the vibrationally excited level of the OD stretching modes. Especially, the transient absorption at $2680 \mathrm{~cm}^{-1}$ has rapid decay time $(\approx 15 \mathrm{ps})$ and it was assigned as the overtone between $v_{3}$ mode and vibrationally excited $v_{1}$ mode $\left(2620 \mathrm{~cm}^{-1}\right)$.

Keywords: Vibrational relaxation; zeolite; water adsoprtion; pump-probe

\section{INTRODUCTION}

Vibrational energy transfer between an adsorbate and a substrate is the key factor in the activity and selectivity of surface reactions. The use of frequency tunable infrared laser pulses in surface vibrational spectroscopy is providing us rich information on the structure and dynamics of adsorbed molecules. Typically, the techniques of infrared-infrared pump-probe spectroscopy have been so successful in revealing the dynamics of molecules adsorbed on solid surfaces

\footnotetext{
* Corresponding author.
} 
[1-4]. Zeolites are crystalline alumino-silicates with large internal surfaces due to the microscopic pores and have been widely investigated because of their catalytic activity. The hydroxyl group located between a silicon and the adjacent aluminum atoms is strongly Brønsted acidic and is responsible for many catalytic reactions. In this report, transient absorption spectra of the system having vibrationally excited OD group of water molecule $\left(\mathrm{D}_{2} \mathrm{O}\right)$ adsorbed on the deuterated zeolitic hydroxyl group (OD) have been measured by the two-color pump-probe technique and possible origin of the signals is discussed.

\section{EXPERIMENTAL}

Infrared pump and probe pulses were generated from the fundamental output of a mode-locked Nd:YAG laser by optical parametric generation/amplification (OPO/OPA) in $\mathrm{LiNbO}_{3}$ crystals. Pretreatment of the sample zeolite was the same as described in Ref. [5]. Selfsupporting disk of zeolite, DM-20 (deuterated $\mathrm{H}$-mordenite zeolite), was exposed to water vapor $\left(\mathrm{D}_{2} \mathrm{O}\right)$ in such a way that one or less water molecule was hydrogen-bonded to a zeolitic OD group.

\section{RESULTS AND DISCUSSION}

Figure 1 is the spectrum observed for the $\mathrm{D}_{2} \mathrm{O}$-adsorbed sample at $123 \mathrm{~K}$. The band at $2730 \mathrm{~cm}^{-1}$ has been assigned to the stretching mode, $v_{3}$, of the OD group of adsorbed water sticking away from the surface (see the inset of Fig. 1). The broad band at $2620 \mathrm{~cm}^{-1}$ is assigned to the OD stretching mode, $v_{1}$, of water molecule which is strongly hydrogen bonded to the zeolite surface [6]. The $v_{1}$ and $v_{3}$ here are used simply to make correspondence to the symmetric and antisymmetric $\mathrm{OD}$ stretching modes of $\mathrm{D}_{2} \mathrm{O}$ in chloroform solution [7]. We denote by $v_{2}$ the DOD deformation mode of the $\mathrm{D}_{2} \mathrm{O}$ moiety. The irradiation by a pump beam tuned at the frequency (Fig. 1, $2730 \mathrm{~cm}^{-1}$ ) of OD group of adsorbed water that is free from the hydrogen bonding gave the bleaching effect and Figure 2 is the transient difference spectrum $\mathrm{A}_{\mathrm{p}}-\mathrm{A}_{0}$ obtained by scanning the frequency of probe beam. The transient absorption peak at 


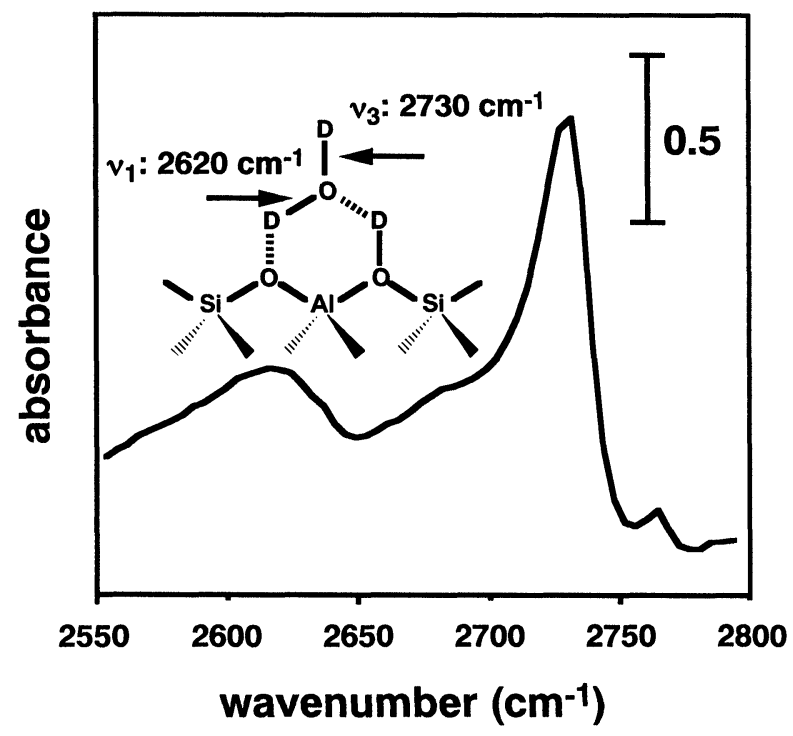

FIGURE 1 Linear absorption spectrum in the $\mathrm{OD}$ stretching region of $\mathrm{D}_{2} \mathrm{O}$-adsorbed DM-20 (deuterated $\mathrm{H}$-mordenite zeolite; $\mathrm{Si} / \mathrm{Al}=10.0$ ) at $123 \mathrm{~K}$. The intense peak at $2730 \mathrm{~cm}^{-1}$ is the OD stretching band of water molecule sticking away from the zeolite surface. The broad peak at $2620 \mathrm{~cm}^{-1}$ is the stretching mode of the OD group water which is under strong hydrogen bonding.

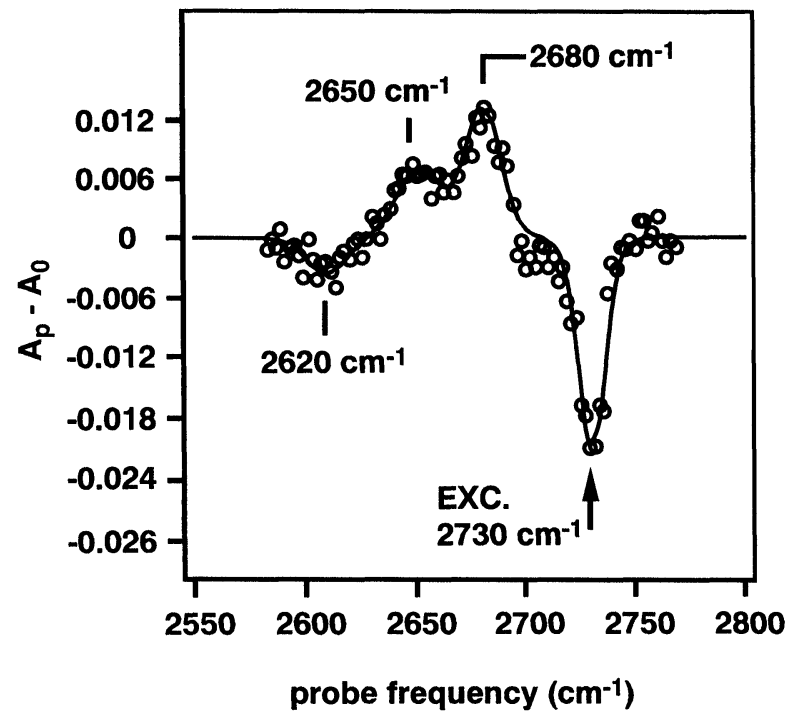

FIGURE 2 Transient ratio spectrum of $\mathrm{D}_{2} \mathrm{O}$-adsorbed DM-20 at $123 \mathrm{~K}$. The ratio spectrum was obtained by subtracting from the spectrum $A_{p}$, which was obtained under the irradiation of pump beam tuned at $2730 \mathrm{~cm}^{-1}$, the spectrum $A_{0}$, obtained without the irradiation by pump beam. The solid line represents the result of fitting using four Gaussian profiles. 
$2650 \mathrm{~cm}^{-1}$ had the decay time of $43 \pm 5 \mathrm{ps}$ at $123 \mathrm{~K}$. The time evolution of this band was very close to the temporal recovery of bleaching signal at $2730 \mathrm{~cm}^{-1}$. This feature and the downshift by $80 \mathrm{~cm}^{-1}$ from the bleaching signal suggested that this transient absorption at $2650 \mathrm{~cm}^{-1}$ is the hot band transition $\left(v_{3}=2 \leftarrow 1\right)$. Transmission of probe beam increased at around $2620 \mathrm{~cm}^{-1}$. This band was assigned to the bleaching of the OD groups of water molecule hydrogen-bonded to the zeolitic hydroxyl group. This bleaching effect implies the occurrence of direct vibrational energy transfer between the two OD stretching modes of adsorbed water. The transient absorption at $2680 \mathrm{~cm}^{-1}$ had rapid decay time $(\approx 15 \mathrm{ps})$ and was assigned to the $\left(v_{1}=1, v_{3}=1\right) \leftarrow\left(v_{1}=1, v_{3}=0\right)$.

\section{References}

[1] Fujino, T., Furuki, M., Kashitani, M., Onda, K., Kubota, J., Kondo, J. N., Wada, A., Domen, K., Hirose, C., Wakabayashi, F., Ishida, M., Goto, F. and Kano, S. S. (1996). J. Chem. Phys., 105, 279.

[2] Kashitani, M., Fujino, T., Fukuyama, K., Kubota, J., Kondo, J. N., Wada, A., Domen, K., Hirose, C., Wakabayashi, F., Ishida, M., Goto, F. and Kano, S. S. (1996). J. Chem. Phys., 105, 6665.

[3] Bonn, M., Brugmans, M. J. P., Kleyn, A. W. and van Santen, R. A. (1995). Chem. Phys. Lett., 233, 309.

[4] Bonn, M., Brugmans, M. J. P., Kleyn, A. W. and van Santen, R. A. (1995). J. Chem. Phys., 102, 2181.

[5] Wakabayashi, F., Kondo, J. N., Domen, K. and Hirose, C. (1995). J. Phys. Chem., 99, 10573.

[6] Pelmenschikov, A. G. and van Santen, R. A. (1993). J. Phys. Chem., 97, 10678.

[7] Graener, H. and Seifert, G. (1993). J. Chem. Phys., 98, 36. 